\title{
Structural and Spectroscopic Characterization of 1-(5-Bromothiophen-2-yl)-3-(4-nitrophenyl)prop-2-en-1-one: An Analysis of Electronic and NLO Properties
}

\author{
Ö. TAMER*, D. AVCI AND Y. AtAlay \\ Sakarya University, Faculty of Arts and Sciences, Department of Physics, 54187, Sakarya, Turkey \\ (Received July 22, 2013; in final form March 9, 2014) \\ The molecular structure of 1-(5-bromothiophen-2-yl)-3-(4-nitrophenyl)prop-2-en-1-one with $\mathrm{C}_{13} \mathrm{H}_{8} \mathrm{BrNO}_{3} \mathrm{~S}$ \\ empirical formula was simulated using B3LYP and CAM-B3LYP levels of density functional theory. After BTNP \\ was optimized on the ground state, its characterization was enhanced via IR, NMR and UV-vis spectroscopies. \\ Conformational analysis was performed based on B3LYP level so as to find the stable conformers of BTNP. Elec- \\ tronic transitions were calculated, and the important contributions from the molecular orbitals to the electronic \\ transitions were investigated. HOMO and LUMO energies were calculated, and obtained energies displayed that \\ charge transfer occurs in BTNP. It was displayed that BTNP is an efficient NLO material due to the coplanar of \\ phenyl-nitro group and carbonyl group. NBO analysis also proved that charge transfer, conjugative interactions \\ and intramolecular hydrogen bonding interactions occur through BTNP.
}

DOI: 10.12693 /APhysPolA.126.679

PACS: 31.15.E-; 33.20.Ea; 33.20.Lg; 42.65.-k; 67.80.Jd

\section{Introduction}

In the past decades, organic compounds with large $\pi$-electron delocalization have attracted extensive interest from different study field such as physics and chemistry due to their large optical nonlinearity which make them demanded materials for optical signal processing, optical communication, photorefractivity, etc. [1-4]. Recently, the search for new nonlinear optic (NLO) materials has been intensified as a result of the growing demand for such materials. These researches are more focused on the organic compounds than their inorganic counterparts due to their high nonlinearity, ultrafast response, high damage resistance, higher possibility to adopt theoretical modeling and flexibility to design new molecules. In this regard, many studies have been devoted to design organic NLO materials [5,6]. Accordingly, the search for new NLO materials is the forefront study field. One approach currently being explored by many researchers is the substitution of benzene rings which are typical D- $\pi-\mathrm{A}$ systems with an electron donating and/or electron withdrawing aromatic ring which can act a donor/ acceptor while modulating the $\pi$ conjugated bridges.

Many experimental studies have reported that replacing the benzene ring with five-membered heteroaromatic rings, such as thiophene, pyrrole and thiazole, results in an enhanced molecular hyperpolarizability $[7,8]$. Additionally, recent theoretical calculations suggest that heterocyclic rings play an important role in the second-order NLO properties of donor-acceptor compounds. In fact, the changes of the molecular nonlinear activity of these

*corresponding author; e-mail: omertamer@sakarya.edu.tr hetero aromatic systems depend not only on the electronic nature of the aromatic rings, but also on the location of these heterocycles in the system $[9,10]$.

Recently, Prabhu and co-workers [11] synthesized 1-(5-bromothiophen-2-yl)-3-(4-nitrophenyl)prop-2-en-1-one (BTNP) single crystal, and investigated its structure by means of X-ray diffraction (XRD), Fourier transform infrared (FTIR), NMR and UV-vis spectroscopies. In the present paper, we focus on the simulating of these spectroscopic studies as well as investigating of some properties related to NLO such as hyperpolarizability. Natural bond orbital (NBO) analysis is performed to investigate the interaction among bonds and conjugative interactions or charge transfer. Additionally, conformational analysis, highest occupied-lowest unoccupied molecular orbit (HOMOLUMO) energies and molecular charges of BTNP are investigated using quantum chemical calculations.

\section{Computational details}

The molecular simulation of BTNP was performed using Gaussian 09 program [12] and the output files were visualized by means of the Gaaussian View 5 software [13]. The optimized structure and vibration spectra of BTNP were predicted using B3LYP (Becke's three-parameter hybrid model using the Lee-Yang-Parr correlation functional) $[14,15]$ and CAM-B3LYP (long range corrected version of B3LYP) [16] with $6-311++\mathrm{G}(\mathrm{d}, \mathrm{p})$ basis set [17]. UV-vis spectra were simulated using time dependent DFT levels (TD/B3LYP and TD/CAM-B3LYP), and the important contributions from molecular orbitals to the electronic transitions were calculated using SWIZARD program [18]. ${ }^{1} \mathrm{H}$ NMR and ${ }^{13} \mathrm{C}$ NMR chemical shifts are calculated within gauge-independent atomic orbital (GIAO) approach [19] which is one of the 
most common approaches for calculating nuclear magnetic shielding tensors. NBO analysis was carried out to investigation of intra- and intermolecular bonding and interaction among bonds and conjugative interactions or charge transfer in BTNP. Density functional theory (DFT) levels were also used to calculate the dipole moment $(\mu)$, the mean polarizability $(\langle\alpha\rangle)$, the anisotropy of the polarizability $(\Delta \alpha)$, and the total first static hyperpolarizability $(\langle\beta\rangle)$. 3D molecular surfaces were simulated, and finally Mulliken and atomic polar tensor (APT) charges were calculated using B3LYP level.

\section{Results and discussion}

\subsection{Geometric optimization and conformational analysis}

The BTNP crystal in triclinic system with a noncentrosymmetric space group $P 1$, with unit cell parameters $a=4.8093(4) \AA, b=5.9428(6) \AA, c=11.5153(11) \AA$, $\alpha=94.999(4), \beta=95.780(3), \gamma=96.396(4)^{\circ}$ and $V=323.79(5) \AA^{3}[11]$, was modeled in the ground state using B3LYP and CAM-B3LYP levels. The optimized structure obtained from B3LYP level along with the experimental one [11] was given in Fig. 1, and obtained bond angles and lengths were presented in Table I as compared with experimental data [11].

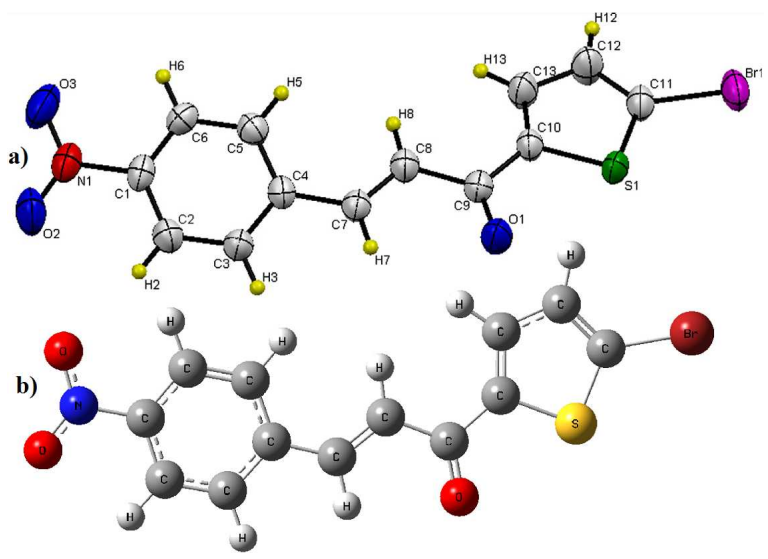

Fig. 1. (a) The molecular structure, showing the atom-numbering scheme [11], (b) the theoretical (obtained from B3LYP level) geometric structure of BTNP.

In the case of free benzene, i.e. without substituent, the bond lengths between the benzene ring carbon atoms are almost equal. The changes in the bond length or frequency and breakdown of regular hexagonal symmetry of the benzene rings are attributed to the changes in charge distribution on the carbon atoms of the benzene ring. The substituent may be either electron withdrawing or electron donating type. With a clearer explanation, $\mathrm{Br}$ substituent is withdrawing in $\sigma$ electron sense but it is $\pi$ electron donating. However, $\mathrm{NO}_{2}$ group is simultaneously $\sigma$ and $\pi$ electron withdrawing [20]. The carbon atoms are bonded to the hydrogen atoms with $\sigma$ bond in ring system and the substitution of the nitro group
TABLE I

Selected theoretical and experimental [11] bond lengths (in $\AA$ ) for BTNP.

\begin{tabular}{c|c|c|c}
\hline \hline \multirow{2}{*}{ Bond lengths } & \multirow{2}{*}{ Experimental } & \multicolumn{2}{|c}{ Theoretical } \\
\cline { 3 - 4 } & & B3LYP & CAM-B3LYP \\
\hline Br1-C11 & $1.874(4)$ & 1.885 & 1.874 \\
S1-C11 & $1.686(5)$ & 1.730 & 1.718 \\
S1-C10 & $1.724(4)$ & 1.750 & 1.735 \\
O2-N1 & $1.232(7)$ & 1.224 & 1.215 \\
O1-C9 & $1.225(6)$ & 1.225 & 1.216 \\
O3-N1 & $1.211(6)$ & 1.225 & 1.215 \\
C11-C12 & $1.355(7)$ & 1.371 & 1.362 \\
C10-C13 & $1.353(7)$ & 1.379 & 1.369 \\
C10-C9 & $1.458(6)$ & 1.471 & 1.470 \\
C9-C8 & $1.491(6)$ & 1.486 & 1.484 \\
C8-C7 & $1.302(7)$ & 1.343 & 1.333 \\
C7-C4 & $1.468(5)$ & 1.462 & 1.469 \\
C4-C3 & $1.380(6)$ & 1.406 & 1.397 \\
C4-C5 & $1.393(6)$ & 1.407 & 1.399 \\
C5-C6 & $1.382(6)$ & 1.385 & 1.380 \\
C6-C1 & $1.376(6)$ & 1.393 & 1.386 \\
C1-C2 & $1.371(6)$ & 1.389 & 1.382 \\
C1-N1 & $1.454(6)$ & 1.477 & 1.473 \\
C3-C2 & $1.380(6)$ & 1.388 & 1.384 \\
C13-C12 & $1.411(8)$ & 1.418 & 1.414
\end{tabular}

decreases the electron density at the ring carbon atom. In the substitution of benzene ring with the $\mathrm{NO}_{2}$ group, the ring carbon atoms exist a large pull on the valence electron cloud of the $\mathrm{H}$ atom resulting in a decrease in the $\mathrm{C}-\mathrm{H}$ bond lengths.

In BTNP crystal the calculated $\mathrm{C}-\mathrm{C}$ bond lengths of benzene ring vary in the ranges $1.385-1.407 \AA$ for B3LYP level and 1.380-1.399 $\AA$ for CAM-B3LYP level. The reason of this difference originates from the substitution of benzene ring. The S1-C11, S1-C10 and $\mathrm{Br} 1-\mathrm{C} 11$ bond lengths are observed as 1.686 (5), 1.724 (4) and 1.874 (4) $\AA$ [11]. In our calculations, these bond lengths were calculated as $1.730,1.750$, and $1.885 \AA$ for B3LYP level. The O1-C9, O2-N1, and O3-N1 bond lengths were defined by the bond lengths of 1.225 (6), 1.232 (7) and 1.211 (6) $\AA$ [11], while these bonds were calculated as $1.225,1.224$, and $1.225 \AA$ for B3LYP level. The $\mathrm{C} 4-\mathrm{C} 7$ and $\mathrm{C} 8-\mathrm{C} 9$ bonds which have single bond character were defined with the bond lengths of 1.462 and $1.486 \AA$, while $\mathrm{C} 7-\mathrm{C} 8$ bond which has single bond character was defined by the bond length of $1.343 \AA$ for B3LYP level.

The conformational analysis has been performed to determine the most stable conformers of BTNP using B3LYP $/ 6-31 G(d)$ level. During the scan process, the whole geometrical parameters were simultaneously relaxed, while the $\mathrm{C} 3-\mathrm{C} 4-\mathrm{C} 7-\mathrm{C} 8$ and $\mathrm{S} 1-\mathrm{C} 10-\mathrm{C} 9-\mathrm{C} 8$ dihedral angles were varied in steps of $10^{\circ}$ ranging from $0^{\circ}$ to $360^{\circ}$.

The potential energy surface (PES) scans for these dihedral angles are presented in Fig. 2. The minimum 

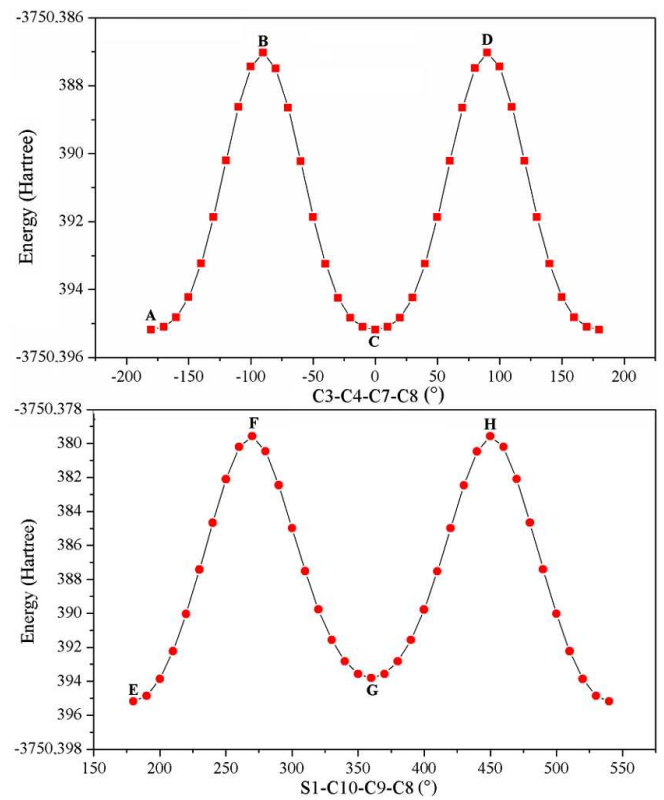

Fig. 2. One-dimensional potential energy surface (PES) scan of the calculated energies vs. dihedral angle of BTNP.
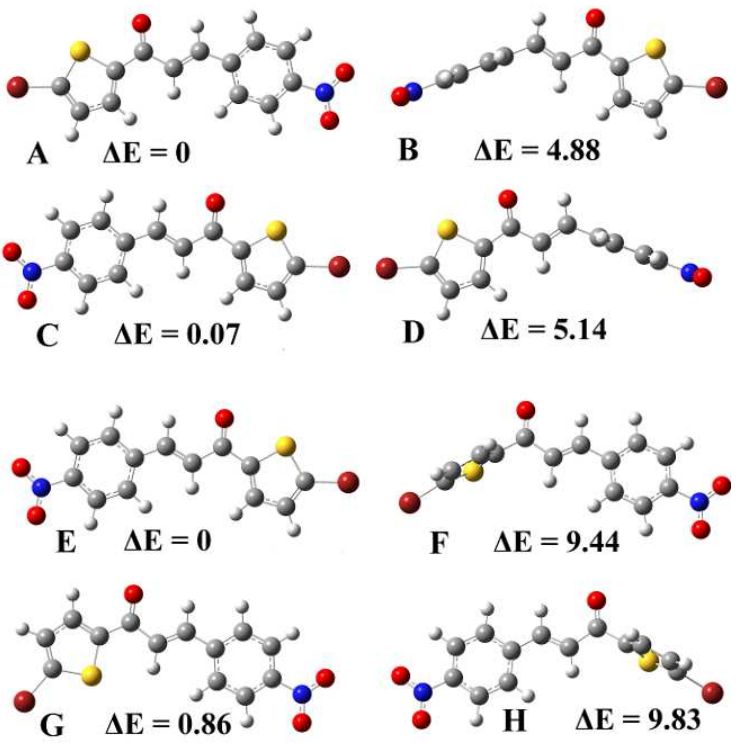

Fig. 3. The highest and lowest energy conformations and relative energies (in $\mathrm{kcal} / \mathrm{mol}$ ) of BTNP using B3LYP level.

and maximum energy conformers on these potential energy surfaces are given in Fig. 3. The stationary points were confirmed by the frequency analysis as minima with all real frequencies and with no imaginary frequency implying no transition state. For the rotation around the S1-C10-C9-C8 dihedral angle, it was seen that there are two maxima on the potential energy surface, which consist of a local maximum and a global maximum. These maxima were calculated at $269.98^{\circ}$ and $449.98^{\circ}$ with the energy values of $-3750.379 \mathrm{Ha}$. From Fig. 4, there were two minima for the rotation around the $\mathrm{S} 1-\mathrm{C} 10-\mathrm{C} 9-\mathrm{C} 8$
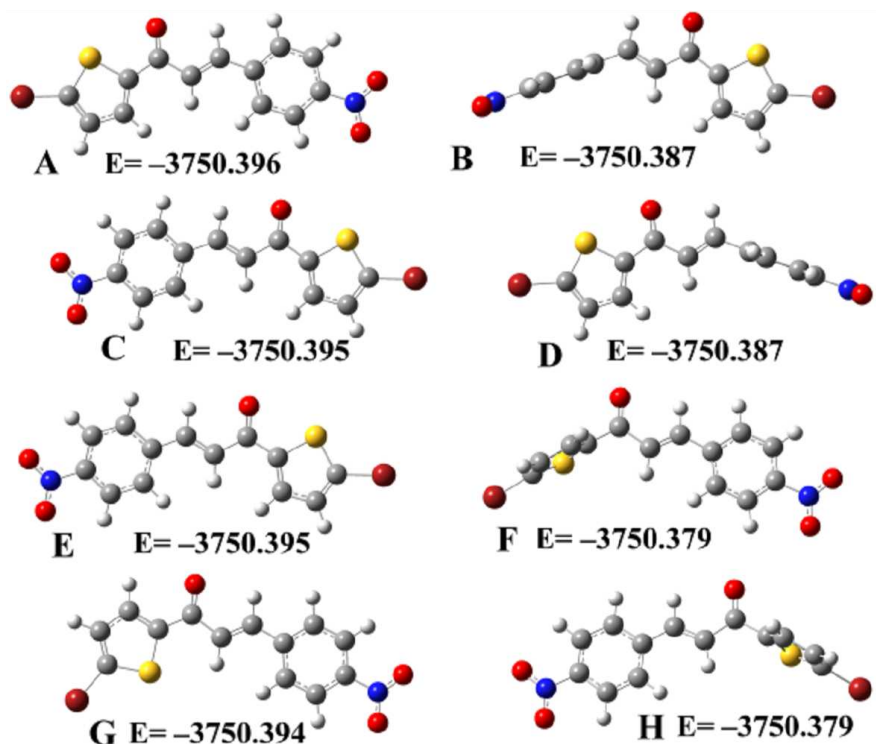

Fig. 4. The highest and lowest energy conformations and energies (in Ha) of BTNP using B3LYP level.

dihedral angle. The local minimum point with the energy value of $-3750.394 \mathrm{Ha}$ was calculated at $359.98^{\circ}$, while global minimum point with the energy value of $-3750.395 \mathrm{Ha}$ was calculated at $179.98^{\circ}$. The highest and lowest energy conformers and relative energies were also given in Fig. 3. The relative energies to the most stable conformer (E) for $\mathrm{S} 1-\mathrm{C} 10-\mathrm{C} 9-\mathrm{C} 8$ dihedral angle were calculated $9.44,0.86$, and 9.83 for F, G, and $\mathrm{H}$ conformers, respectively.

\subsection{Vibrational analysis}

The vibration spectra of BTNP were simulated at B3LYP and CAM-B3LYP levels with the 6-311++G(d,p) basis set. It is well known that DFT levels overestimate the vibrational frequencies, and this overestimation of the computed wave numbers is quite systematic and can be corrected by applying appropriate scaling factors or scaling equations. In this connection, the scaling factors, 0.9899 for B3LYP and 0.9700 for CAM-B3LYP were used to correct anharmonicity and neglected part of electron correlation $[21,22]$. The vibrational spectra along with the experimental one [11] were presented in Fig. 5, and the obtained data are summarized in Table II as compared with the each other.

In the aromatic compounds, the $\mathrm{C}-\mathrm{H}$ stretching vibrations normally occur at $3100-3000 \mathrm{~cm}^{-1}$. In this region, the bands are not affected appreciably by the nature of substituents [23]. The $\mathrm{C}-\mathrm{H}$ stretching vibration was observed at $3078 \mathrm{~cm}^{-1}$ [11], and these peaks were calculated at 3178 and $3163 \mathrm{~cm}^{-1}$ for B3LYP level and 3171 and $3157 \mathrm{~cm}^{-1}$ for CAM-B3LYP level. The aromatic ring in-plane $\mathrm{C}-\mathrm{H}$ bending vibrations are usually weak and observed in the region $1300-1000 \mathrm{~cm}^{-1}$, while the out-of-plane ones lie in the region $900-650 \mathrm{~cm}^{-1}$ [24]. In our calculations in-plane $\mathrm{C}-\mathrm{H}$ bending vibrations are assigned at the wave number regions of 1329-1082 and 


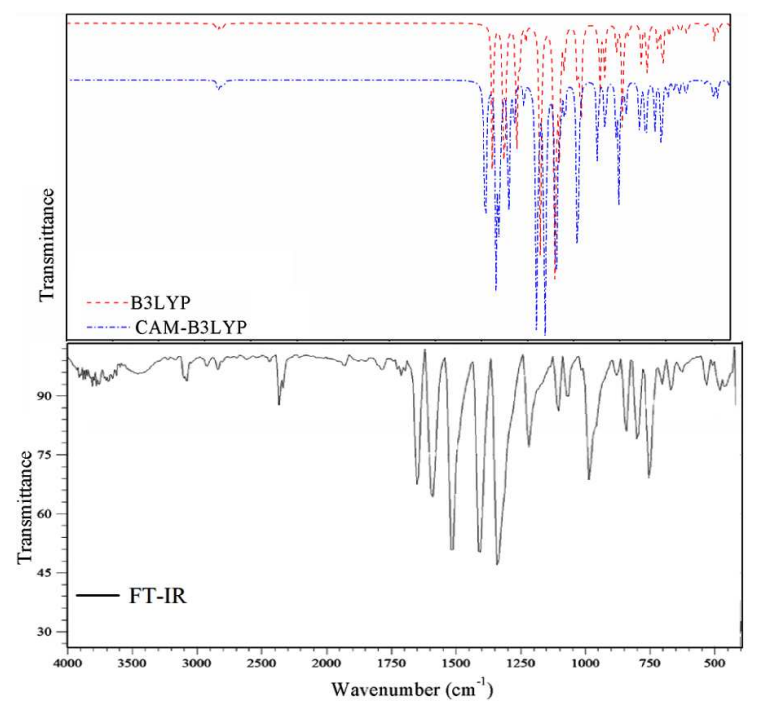

Fig. 5. Theoretical and experimental [11] IR spectra of HBAH.

TABLE II

Selected experimental [11] and theoretical vibration wave numbers (in $\mathrm{cm}^{-1}$ ) for BTNP.

\begin{tabular}{|c|c|c|c|c|c|}
\hline \multirow{3}{*}{ Assignments } & \multirow{3}{*}{ Experimental } & \multicolumn{4}{|c|}{ Theoretical } \\
\hline & & \multicolumn{2}{|c|}{ B3LYP } & \multicolumn{2}{|c|}{ CAMB3LYP } \\
\hline & & $\begin{array}{l}\text { Scaled } \\
\text { freq. }{ }^{a}\end{array}$ & $I_{\mathrm{IR}}^{b}$ & $\begin{array}{l}\text { Scaled } \\
\text { freq. }^{a}\end{array}$ & $I_{\mathrm{IR}}^{b}$ \\
\hline$\nu \mathrm{CH}$ & 3078 & 3178 & 6 & 3171 & 6 \\
\hline$\nu \mathrm{CH}$ & - & 3163 & 5 & 3157 & 4 \\
\hline$\nu \mathrm{CO}$ & 1650 & 1689 & 206 & 1728 & 214 \\
\hline$\nu \mathrm{CC}+\nu \mathrm{NO}$ & 1569 & 1630 & 205 & 1669 & 230 \\
\hline$\nu \mathrm{CC}+\nu \mathrm{NO}$ & - & 1618 & 99 & 1655 & 141 \\
\hline$\nu \mathrm{NO}$ & 1519 & 1558 & 195 & 1601 & 166 \\
\hline$\nu \mathrm{CC}$ & - & 1543 & 56 & 1571 & 43 \\
\hline$\nu \mathrm{CC}$ & 1404 & 1430 & 454 & 1449 & 400 \\
\hline$\nu \mathrm{NO}$ & 1312 & 1354 & 91 & 1404 & 486 \\
\hline$\nu \mathrm{NO}+\nu \mathrm{CC}+\nu \mathrm{NC}$ & - & 1349 & 606 & 1347 & 164 \\
\hline$\nu \mathrm{CC}+\beta \mathrm{CH}$ & - & 1329 & 146 & 1342 & 154 \\
\hline$\beta \mathrm{CH}$ & - & 1324 & 68 & 1321 & 38 \\
\hline$\beta \mathrm{CH}$ & 1211 & 1228 & 86 & 1230 & 136 \\
\hline$\nu \mathrm{CC}+\beta \mathrm{CH}$ & - & 1217 & 48 & 1223 & 83 \\
\hline$\beta \mathrm{CH}$ & - & 1209 & 106 & 1211 & 89 \\
\hline$\nu \mathrm{CN}$ & 1103 & 1106 & 84 & 1120 & 57 \\
\hline$\beta \mathrm{CH}$ & 1064 & 1082 & 66 & 1078 & 52 \\
\hline$\gamma \mathrm{CH}$ & 987 & 1015 & 28 & 1019 & 30 \\
\hline$\beta \mathrm{CC}$ & - & 984 & 139 & 1003 & 100 \\
\hline$\nu \mathrm{CBr}+\beta \mathrm{CC}$ & - & 951 & 135 & 966 & 30 \\
\hline$\beta \mathrm{CC}+\beta \mathrm{NO}$ & 840 & 854 & 30 & 863 & 47 \\
\hline$\gamma \mathrm{CH}$ & & 848 & 45 & 809 & 39 \\
\hline$\gamma \mathrm{CC}+\nu \mathrm{CBr}$ & 756 & 761 & 131 & 757 & 74 \\
\hline
\end{tabular}

1342-1078 $\mathrm{cm}^{-1}$ for B3LYP and CAM-B3LYP levels, respectively. The peak at $848 \mathrm{~cm}^{-1}$ for B3LYP is assigned as the out of plane $\mathrm{C}-\mathrm{H}$ bending vibration.

The IR spectrum shows the characteristic absorption bands at $1650 \mathrm{~cm}^{-1}$ due to $\mathrm{C}=\mathrm{O}$ group of $\alpha, \beta$-unsaturated carbonyl compound [11], and that prove the formation of 1-(5-bromothiophen-2-yl)-3-(4- -nitrophenyl)prop-2-en-1-one. This characteristic $\mathrm{C}=\mathrm{O}$ band is calculated at $1689 \mathrm{~cm}^{-1}$ for B3LYP level and $1728 \mathrm{~cm}^{-1}$ for CAM-B3LYP level. The $\mathrm{NO}_{2}$ stretching vibrations which are another characteristic vibration mode were observed at $1519 \mathrm{~cm}^{-1}$ for asymmetric stretch and $1312 \mathrm{~cm}^{-1}$ for symmetric stretch [11]. It is well known that asymmetric vibrations appear at higher frequencies than symmetric ones for nitro group vibrations. These vibrations were assigned at 1558 and $1354 \mathrm{~cm}^{-1}$ for B3LYP level and 1601 and $1404 \mathrm{~cm}^{-1}$ for CCAM-B3LYP level, respectively.

The ring $\mathrm{C}=\mathrm{C}$ stretching vibrations usually occur in the region $1625-1280 \mathrm{~cm}^{-1}$ [25]. For aromatic six-membered rings such as benzene, there are two or three bands in this region due to skeletal vibrations, the strongest one at about $1500 \mathrm{~cm}^{-1}$ [26]. The peak observed at $1569 \mathrm{~cm}^{-1}$ was assigned the $\mathrm{C}=\mathrm{C}$ stretching vibration [11]. This vibration mode was calculated at the ranges of $1630-1217 \mathrm{~cm}^{-1}$ for B3LYP level and 1669 $1223 \mathrm{~cm}^{-1}$ for CAM-B3LYP level. The calculated peaks at 984 and $854 \mathrm{~cm}^{-1}$ for B3LYP level were attributed to in plane $\mathrm{C}-\mathrm{C}$ bending vibrations. The out of plane $\mathrm{C}-\mathrm{C}$ vibration was calculated at 761 and $757 \mathrm{~cm}^{-1}$ for B3LYP and CAM-B3LYP levels, respectively.

\subsection{NMR studies}

GIAO method which is used in calculating nuclear magnetic shielding tensors has proven to be quite accepted and accurate, in particular when applied in the context of highly correlated $a b$ initio methods. The characterization of BTNP was further enhanced by the use of ${ }^{1} \mathrm{H}$ and ${ }^{13} \mathrm{C}$ NMR calculations, and obtained chemical shift data were compared with experimental ones [11] in Table III.

The oxygen reduces the electron density of carbon atom $\mathrm{C}$, so its ${ }^{13} \mathrm{C}$ NMR peak was calculated in the downfield at 181.33 and $181.46 \mathrm{ppm}$ for B3LYP and CAM-B3LYP levels, respectively. The carbon atoms $\mathrm{C} 11, \mathrm{C} 10$, and $\mathrm{C} 1$ were also calculated in the down field due to the deshielding effect of the electronegative atoms $\mathrm{Br} 1, \mathrm{~S} 1$, and $\mathrm{N} 1$ atoms. These carbons give signals at 161.35, 161.05, and $156.13 \mathrm{ppm}$ for B3LYP level and 155.65, 155.30, and $152.77 \mathrm{ppm}$ for CAM-B3LYP level, respectively. Aromatic carbons gave signals in overlapped areas of the spectrum with chemical shift values from 100 to $150 \mathrm{ppm}$ [27]. In our calculations, aromatic carbons gave signals in the range of $146.78-128.49 \mathrm{ppm}$ for B3LYP and 146.17-126.53 ppm CAM-B3LYP. The influence of electronegative bromine, nitrogen, sulfur and oxygen atoms on $\mathrm{C} 8$ was negligibly small and thus was observed in the upfield at 123.31 and $121.38 \mathrm{ppm}$, respectively.

The NMR peak of hydrogen attached or nearby electron withdrawing atom or group appears in the downfield. The proton signals originating from $\mathrm{H} 6$ and $\mathrm{H} 2$ atoms were observed at 8.29 and $8.28 \mathrm{ppm}$ [11]. These signals are calculated at 8.61 and $8.27 \mathrm{ppm}$ for B3LYP and 8.68 and $8.49 \mathrm{ppm}$ for CAM-B3LYP level, respectively. Since the $\mathrm{H} 6$ and $\mathrm{H} 2$ protons are nearer to electron 
TABLE III

Theoretical and experimental $[11]{ }^{13} \mathrm{C}$ and ${ }^{1} \mathrm{H}$ isotropic chemical shifts (with respect to TMS, all values in $\mathrm{ppm}$ ) for BTNP.

\begin{tabular}{|c|c|c|c|}
\hline \multirow{2}{*}{ Atom } & \multirow{2}{*}{ Experimental } & \multicolumn{2}{|c|}{ Theoretical } \\
\hline & & B3LYP & CAMB3LYP \\
\hline \multicolumn{4}{|c|}{$\mathrm{H}$} \\
\hline H6 & 8.29 & 8.61 & 8.68 \\
\hline $\mathrm{H} 2$ & 8.28 & 8.27 & 8.49 \\
\hline $\mathrm{H} 5$ & 7.78 & 8.15 & 8.25 \\
\hline $\mathrm{H} 7$ & 7.30 & 8.05 & 8.21 \\
\hline H3 & 7.78 & 7.70 & 7.74 \\
\hline H13 & 7.70 & 7.51 & 7.57 \\
\hline $\mathrm{H} 8$ & 7.18 & 7.44 & 7.55 \\
\hline H12 & 7.80 & 7.01 & 7.03 \\
\hline \multicolumn{4}{|c|}{${ }^{13} \mathrm{C}$} \\
\hline C9 & - & 181.33 & 181.46 \\
\hline $\mathrm{C} 11$ & - & 161.35 & 155.65 \\
\hline $\mathrm{C} 10$ & - & 161.05 & 155.30 \\
\hline $\mathrm{C} 1$ & - & 156.13 & 152.77 \\
\hline $\mathrm{C} 4$ & - & 146.78 & 146.17 \\
\hline $\mathrm{C} 7$ & - & 145.71 & 144.15 \\
\hline C3 & - & 138.38 & 136.21 \\
\hline $\mathrm{C} 12$ & - & 134.68 & 132.01 \\
\hline $\mathrm{C} 13$ & - & 132.87 & 131.64 \\
\hline $\mathrm{C} 2$ & - & 129.62 & 128.38 \\
\hline $\mathrm{C} 6$ & - & 129.05 & 127.67 \\
\hline $\mathrm{C} 5$ & - & 128.49 & 126.53 \\
\hline $\mathrm{C} 8$ & - & 123.31 & 121.38 \\
\hline
\end{tabular}

withdrawing $\mathrm{NO}_{2}$ group than $\mathrm{H} 5$ and $\mathrm{H} 3$ protons, these protons give peaks at the more downfield region. The other aromatic protons, $\mathrm{H} 3, \mathrm{H} 5, \mathrm{H} 12$, and $\mathrm{H} 13$, gave signals in the expected region [28]. The $\mathrm{H} 7$ and $\mathrm{H} 8$ proton signals observed at 7.30 and $7.18 \mathrm{ppm}$ [11] were calculated at 8.05 and $7.44 \mathrm{ppm}$ for B3LYP, respectively.

\subsection{Electronic properties}

The HOMO and LUMO energies are very important parameters for quantum chemistry. LUMO, which is an electron acceptor, represents the ability to obtain an electron, while HOMO, which is an electron donor, represents the ability to donate an electron [29]. Energy gap between HOMO and LUMO characterizes the molecular chemical stability and it is a critical parameter in determining molecular electrical transport properties because it is a measure of electron conductivity.

HOMO and LUMO energies were calculated as -7.078 and $-3.515 \mathrm{eV}$ for B3LYP level and -8.462 and $-2.298 \mathrm{eV}$ for CAM-B3LYP level, respectively. The energy gap between the HOMO and LUMO orbital was predicted as 3.563 and $6.164 \mathrm{eV}$, respectively. It is well known that lower HOMO-LUMO gap results in better charge transportation. Frontier molecular orbitals (FMOs) are given in Fig. 6. From Fig. 6,

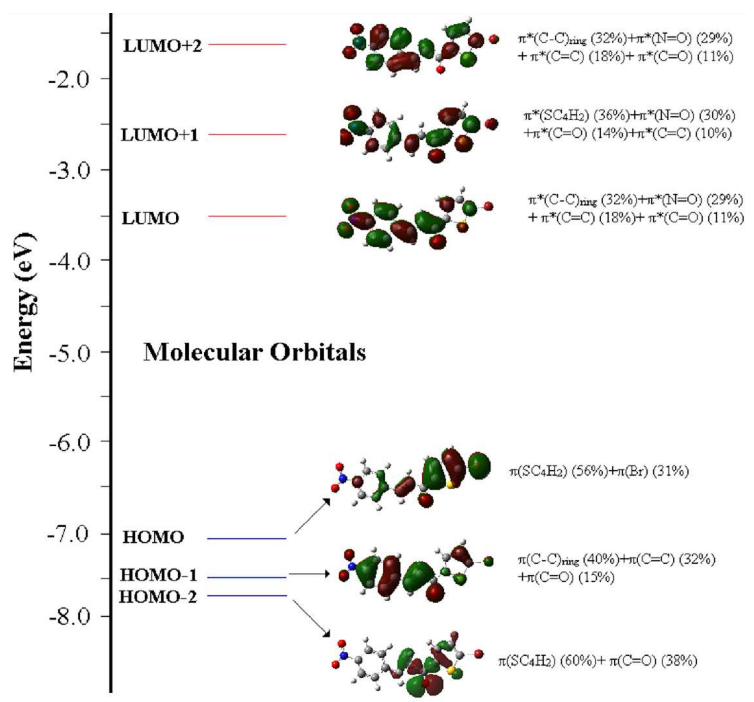

Fig. 6. The frontier molecular orbitals of BTNP (obtained from B3LYP).

HOMO orbitals are localized on mainly $\pi\left(\mathrm{SC}_{4} \mathrm{H}_{2}\right)(56 \%)$ and $\pi(\mathrm{Br})(31 \%)$. LUMO orbitals are located on $\pi^{*}(\mathrm{C}-\mathrm{C})_{\text {ring }}(32 \%), \pi^{*}(\mathrm{~N}=\mathrm{O})(29 \%), \pi^{*}(\mathrm{C}=\mathrm{C})(18 \%)$, and $\pi^{*}(\mathrm{C}=\mathrm{O})(11 \%)$.

Electronegativity $(\chi)$ and chemical hardness $(\eta)$ were also predicted by using the frontier molecular orbital energies [30-32]. While $\chi$ value was calculated as $1.7815 \mathrm{eV}$ and $3.082 \mathrm{eV}, \eta$ values was calculated as $5.2965 \mathrm{eV}$ and $5.3800 \mathrm{eV}$ for B3LYP and CAM-B3LYP levels, respectively. For any two molecules, electron will be partially transferred from the one of low $\chi$ to that of high $\chi$ (electrons flow from high chemical potential to low chemical potential).

TABLE IV

Theoretical and experimental [11] electronic transitions, oscillator strength and major contributions for the title compound.

\begin{tabular}{c|c|c|c|c|c}
\hline \hline \multirow{2}{*}{$\begin{array}{c}\text { Experimental } \\
{[\mathrm{nm}]}\end{array}$} & \multicolumn{4}{|c}{ Theoretical } \\
\cline { 2 - 6 } & \multicolumn{2}{|c|}{ B3LYP } & \multicolumn{2}{c}{ CAM-B3LYP } & Major contributions \\
\hline 420 & 385 & 0.4220 & 308 & 1.1297 & $\mathrm{H}-2 \rightarrow \mathrm{L}(+99 \%)$ \\
- & 334 & 0.5688 & - & - & $\mathrm{H}-2 \rightarrow \mathrm{L}+1(+92 \%)$ \\
\hline
\end{tabular}

H:HOMO, L:LUMO

The UV-vis spectra of the title compound were calculated using the time dependent density functional theory (TD-DFT). Major contributions to the electronic transitions were designated with the aid of SWIZARD program, and obtained results were given in Table IV. The absorption band experimentally observed at $420 \mathrm{~nm}$ was calculated at 385 and $334 \mathrm{~nm}$ for B3LYP level and $308 \mathrm{~nm}$ for CAM-B3LYP level. The absorption peak calculated at $385 \mathrm{~nm}$ for B3LYP was formed by the transition from HOMO-2 orbital to the LUMO orbital with the $99 \%$ purity. From Fig. 6 , the transition of $\mathrm{H}-2 \rightarrow \mathrm{L}$ is represented by the transitions from $\pi\left(\mathrm{SC}_{4} \mathrm{H}_{2}\right)(60 \%)$ and $\pi(\mathrm{C}=\mathrm{O})(38 \%)$ to the $\pi^{*}(\mathrm{C}-\mathrm{C})_{\text {ring }}(32 \%), \pi^{*}(\mathrm{~N}=\mathrm{O})$ 
$(29 \%), \pi^{*}(\mathrm{C}=\mathrm{C})(18 \%)$ and $\pi^{*}(\mathrm{C}=\mathrm{O})(11 \%)$. Thus, these transitions proved that the charge transfer occurs in BTNP.

\subsection{NBO analysis}

NBO analysis provides an efficient method for studying intra- and inter molecular bonding and interaction among bonds, and provides a convenient basis for investigating charge transfer or conjugative interaction in molecular systems [33]. The larger $E(2)$ value implies the more intensive interaction between electron donors and electron acceptors, in other words, the more donating tendency from electron donors to electron acceptors and the greater the extent of conjugation of the whole system.

The interactions result in a loss of occupancy from the localized NBO of the idealized Lewis structure into an empty non-Lewis orbital. For each donor $(i)$ and acceptor $(j)$, the stabilization energy $E(2)$ associated with the delocalization $i \rightarrow j$ is estimated as [34]:

$$
E(2)=\Delta E_{i j}=q_{i} \frac{F(i, j)^{2}}{\varepsilon_{j}-\varepsilon_{i}^{\prime}},
$$

where $q_{i}$ is the donor orbital occupancy, $\varepsilon_{i}$ and $\varepsilon_{j}$ are diagonal elements and $F(i, j)$ is the off-diagonal NBO Fock matrix element.

Second-order perturbation theory analysis of Fock matrix on NBO basis for BTNP

TABLE V (obtained from B3LYP level).

\begin{tabular}{|c|c|c|c|c|c|c|c|c|}
\hline Type & Donor & $\begin{array}{c}\mathrm{ED}(\mathrm{i}) \\
(\mathrm{e})\end{array}$ & Type & Acceptor & $\begin{array}{c}\mathrm{ED}(\mathrm{i}) \\
(\mathrm{e})\end{array}$ & $\begin{array}{c}\mathrm{E}(2)^{a} \\
{[\mathrm{kcal} / \mathrm{mol}]}\end{array}$ & $\begin{array}{c}E(j)-E(i)^{b} \\
\text { [a.u.] }\end{array}$ & $\begin{array}{l}F(i j)^{c} \\
\text { [a.u.] }\end{array}$ \\
\hline$\sigma$ & C11-C12 & 1.98657 & $\sigma^{*}$ & C12-C13 & 0.36560 & 2.73 & 1.29 & 0.053 \\
\hline$\pi$ & $\mathrm{C} 11-\mathrm{C} 12$ & 1.83025 & $\pi^{*}$ & $\mathrm{C} 11-\mathrm{C} 12$ & 0.04159 & 1.36 & 0.29 & 0.019 \\
\hline$\pi$ & $\mathrm{C} 11-\mathrm{C} 12$ & 1.83025 & $\pi^{*}$ & $\mathrm{C} 10-\mathrm{C} 13$ & 0.35047 & 15.76 & 0.31 & 0.065 \\
\hline$\pi$ & $\mathrm{C} 10-\mathrm{C} 13$ & 1.79343 & $\pi^{*}$ & $\mathrm{C} 11-\mathrm{C} 12$ & 0.04159 & 15.11 & 0.27 & 0.060 \\
\hline$\pi$ & $\mathrm{C} 10-\mathrm{C} 13$ & 1.79343 & $\pi^{*}$ & $\mathrm{C} 9-\mathrm{O} 1$ & 0.23602 & 20.82 & 0.30 & 0.071 \\
\hline$\sigma$ & $\mathrm{C} 7-\mathrm{C} 8$ & 1.97527 & $\sigma^{*}$ & $\mathrm{~N} 1-\mathrm{O} 2$ & 0.05462 & 35.59 & 5.66 & 0.409 \\
\hline$\pi$ & $\mathrm{C} 7-\mathrm{C} 8$ & 1.83702 & $\pi^{*}$ & $\mathrm{C} 9-\mathrm{O} 1$ & 0.23602 & 19.48 & 0.30 & 0.069 \\
\hline$\pi$ & $\mathrm{C} 7-\mathrm{C} 8$ & 1.83702 & $\pi^{*}$ & $\mathrm{C} 3-\mathrm{C} 4$ & 0.36008 & 12.68 & 0.30 & 0.058 \\
\hline$\pi$ & $\mathrm{C} 7-\mathrm{C} 8$ & 1.83702 & $\pi^{*}$ & $\mathrm{~N} 1-\mathrm{O} 2$ & 0.62424 & 4.29 & 1.76 & 0.088 \\
\hline$\sigma$ & $\mathrm{C} 7-\mathrm{C} 4$ & 1.97535 & $\sigma^{*}$ & $\mathrm{~N} 1-\mathrm{O} 2$ & 0.05462 & 25.51 & 5.59 & 0.346 \\
\hline$\sigma$ & $\mathrm{C} 7-\mathrm{H} 7$ & 1.97271 & $\sigma^{*}$ & $\mathrm{~N} 1-\mathrm{O} 2$ & 0.05462 & 73.88 & 5.41 & 0.568 \\
\hline$\pi$ & $\mathrm{C} 3-\mathrm{C} 4$ & 1.59664 & $\pi^{*}$ & $\mathrm{C} 7-\mathrm{C} 8$ & 0.09509 & 15.37 & 0.30 & 0.066 \\
\hline$\pi$ & $\mathrm{C} 3-\mathrm{C} 4$ & 1.59664 & $\pi^{*}$ & $\mathrm{C} 5-\mathrm{C} 6$ & 0.26972 & 17.45 & 0.28 & 0.065 \\
\hline$\pi$ & $\mathrm{C} 3-\mathrm{C} 4$ & 1.59664 & $\pi^{*}$ & $\mathrm{C} 1-\mathrm{C} 2$ & 0.37200 & 23.22 & 0.27 & 0.071 \\
\hline$\pi$ & $\mathrm{C} 5-\mathrm{C} 6$ & 1.66482 & $\pi^{*}$ & $\mathrm{C} 3-\mathrm{C} 4$ & 0.36008 & 20.50 & 0.29 & 0.066 \\
\hline$\pi$ & $\mathrm{C} 5-\mathrm{C} 6$ & 1.66482 & $\pi^{*}$ & $\mathrm{C} 1-\mathrm{C} 2$ & 0.37200 & 19.74 & 0.28 & 0.067 \\
\hline$\pi$ & $\mathrm{C} 1-\mathrm{C} 2$ & 1.64055 & $\pi^{*}$ & $\mathrm{C} 3-\mathrm{C} 4$ & 0.36008 & 18.02 & 0.30 & 0.065 \\
\hline$\pi$ & $\mathrm{C} 1-\mathrm{C} 2$ & 1.64055 & $\pi^{*}$ & $\mathrm{C} 5-\mathrm{C} 6$ & 0.26972 & 19.74 & 0.30 & 0.070 \\
\hline$\sigma$ & $\mathrm{C} 1-\mathrm{C} 2$ & 1.97568 & $\sigma^{*}$ & $\mathrm{C} 2-\mathrm{C} 3$ & 0.01367 & 2.68 & 1.30 & 0.053 \\
\hline \multirow[t]{9}{*}{$\sigma$} & $\mathrm{C} 1-\mathrm{C} 2$ & 1.97568 & $\sigma^{*}$ & $\mathrm{C} 1-\mathrm{C} 6$ & 0.02258 & 4.67 & 1.28 & 0.069 \\
\hline & $\mathrm{LP}(2) \mathrm{S} 1$ & 1.58926 & $\pi^{*}$ & C11-C12 & 0.04159 & 25.85 & 0.24 & 0.071 \\
\hline & $\mathrm{LP}(2) \mathrm{S} 1$ & 1.58926 & $\pi^{*}$ & $\mathrm{C} 10-\mathrm{C} 13$ & 0.35047 & 21.40 & 0.26 & 0.067 \\
\hline & $\mathrm{LP}(3) \mathrm{Br} 1$ & 1.91978 & $\pi^{*}$ & $\mathrm{C} 11-\mathrm{C} 12$ & 0.04159 & 12.02 & 0.29 & 0.057 \\
\hline & $\mathrm{LP}(2) \mathrm{O} 1$ & 1.88504 & $\sigma^{*}$ & C9-C10 & 0.06103 & 18.00 & 0.71 & 0.103 \\
\hline & $\mathrm{LP}(2) \mathrm{O} 1$ & 1.88504 & $\pi^{*}$ & $\mathrm{C} 8-\mathrm{C} 9$ & 0.06164 & 19.42 & 0.68 & 0.104 \\
\hline & $\mathrm{LP}(2) \mathrm{O} 3$ & 1.89935 & $\sigma^{*}$ & $\mathrm{C} 1-\mathrm{N} 1$ & 0.10606 & 12.07 & 0.57 & 0.074 \\
\hline & $\mathrm{LP}(2) \mathrm{O} 2$ & 1.89889 & $\sigma^{*}$ & $\mathrm{C} 1-\mathrm{N} 1$ & 0.10606 & 12.21 & 0.57 & 0.075 \\
\hline & $\mathrm{LP}(2) \mathrm{O} 2$ & 1.89889 & $\sigma^{*}$ & $\mathrm{~N} 1-\mathrm{O} 3$ & 0.05488 & 18.71 & 0.73 & 0.106 \\
\hline
\end{tabular}

\footnotetext{
$\mathrm{ED}=$ electron density.

${ }^{a} E(2)$ means energy of hyperconjugative interactions (stabilization energy).

${ }^{b}$ Energy difference between donor and acceptor $i$ and $j$ NBO orbitals.

${ }^{c} F(i, j)$ is the Fock matrix element between $i$ and $j$ NBO orbitals.
}

The strong intramolecular hyperconjugative interaction of the $\sigma$ and $\pi$ electrons of $\mathrm{C}-\mathrm{C}$ to the anti $\mathrm{C}-\mathrm{C}$ bond of the benzene ring leads to stabilization of some part of the benzene ring as evident from Table V. For ex- 
ample, the intramolecular hyperconjugative interaction of $\sigma(\mathrm{C} 1-\mathrm{C} 2)$ distributes to $\sigma^{*}(\mathrm{C} 2-\mathrm{C} 3)$ and $(\mathrm{C} 1-\mathrm{C} 6)$ leading to stabilization of 2.68 and $4.67 \mathrm{kcal} / \mathrm{mol}$, respectively. This enhances further conjugation with antibonding orbital of $\pi^{*}(\mathrm{C} 3-\mathrm{C} 4), \pi^{*}$ (C5-C6), which leads to strong delocalization of 18.02 and $19.74 \mathrm{kcal} / \mathrm{mol}$, respectively. The intramolecular interactions are formed by the orbital overlap between the lone pair LP(2) O1 and antibond $\sigma^{*}(\mathrm{C} 9-\mathrm{C} 10)$ and $\pi^{*}(\mathrm{C} 8-\mathrm{C} 9)$ orbitals which results in intramolecular charge transfer (ICT) causing stabilization of the system. NBO analysis shows that intramolecular charge transfer in BTNP from $\pi(\mathrm{C} 3-\mathrm{C} 4)$ to $\pi^{*}(\mathrm{C} 1-\mathrm{C} 2)$ with the stabilization energy of $23.22 \mathrm{kcal} / \mathrm{mol}$ and from $\pi(\mathrm{C} 5-\mathrm{C} 6)$ to $\pi^{*}(\mathrm{C} 3-\mathrm{C} 4)$ with the stabilization energy of $20.50 \mathrm{kcal} / \mathrm{mol}$. The other examples of these interactions are summarized in Table $\mathrm{V}$.

The energy contribution $\mathrm{LP}(2) \mathrm{S} 1 \rightarrow \pi^{*}(\mathrm{C} 11-\mathrm{C} 12)$, $\mathrm{LP}(3) \mathrm{Br} 1 \rightarrow \pi^{*}(\mathrm{C} 11-\mathrm{C} 12), \mathrm{LP}(2) \mathrm{O} 2 \rightarrow \sigma^{*}(\mathrm{~N} 1-\mathrm{O} 3)$ and $\mathrm{LP}(2) \mathrm{O} 3 \rightarrow \sigma^{*}(\mathrm{~N} 1-\mathrm{O} 3)$ are $28.85,12.02,18.71$, and $12.07 \mathrm{kcal} / \mathrm{mol}$, respectively, and hence there is a possibility for delocalization of lone pair (LP) of electrons. These interactions are observed as increase in electron density (ED) in $\mathrm{C}-\mathrm{C}$ antibonding orbital that weakens the respective bonds. The electron density of conjugated bond of aromatic ring $(\approx 1.99 e)$ clearly demonstrates strong delocalization. The increased electron density at the bromine atom leads to the elongation of $\mathrm{C}-\mathrm{Br}$ bond and a lowering of the $\mathrm{C}-\mathrm{Br}$ stretching wave number. The electron density (ED) is transferred from the $n(\mathrm{Br})$ to the antibonding $\pi^{*}$ orbital of the $\mathrm{C}-\mathrm{C}$ bond, explaining both the elongation and the red shift.

\subsection{Electric properties}

Dipole moment is an important parameter in structural chemistry, and it can be used as a descriptor to illustrate the charge transfer through the molecule. The direction of the dipole moment vector in a molecule depends on the centers of positive and negative charges. The dipole moment for BTNP is calculated as $3.9696 \mathrm{D}$ for B3LYP level and 3.6290 D for CAM-B3LYP level with maximum contribution from $x$. In $z$ directions, dipole moment can be negligible (see in Table VI).

The intramolecular charge transfer from the electron donating group to the electron withdrawing group through single-double bond can induce large variations of both the molecular dipole moment as well as molecular polarizability, making IR and Raman activity strong at the same time. As can be seen in Table II, the $\mathrm{C}=\mathrm{O}$, $\mathrm{N}=\mathrm{O}$, and $\mathrm{C}=\mathrm{C}$ stretching vibrations were found to be strong and simultaneously active in IR. These vibrations were calculated at 1689,1630 , and $1558 \mathrm{~cm}^{-1}$ for B3LYP, respectively. Accordingly, these active stretching vibration modes demonstrate that charge transfer occurs in BTNP. Additionally, the transfer of $\pi$ electron from donating group to the withdrawing group makes the highly polarizable molecule. Accordingly, intramolecular charge transfer interactions may be responsible for the NLO properties. NLO properties get enhanced by the substitution of molecule with carbonyl and nitro group which

\section{TABLE VI}

Total static dipole moment $(\mu$, in $\mathrm{D})$, the mean polarizability $\left(\langle\alpha\rangle\right.$, in $10^{-24}$ esu), the anisotropy of the polarizability ( $\Delta \alpha$, in $10^{-24}$ esu), the mean first-order hyperpolarizability $\left(\langle\beta\rangle\right.$, in $\left.10^{-30} \mathrm{esu}\right)$ for BTNP.

\begin{tabular}{c|c|c|c}
\hline \hline Property & B3LYP & & CAM-B3LYP \\
\hline$\mu_{x}$ & 3.4684 & & 3.0872 \\
$\mu_{y}$ & -1.9306 & & -1.9077 \\
$\mu_{z}$ & -0.0166 & & 0.0004 \\
$\mu$ & 3.9696 & & 3.6290 \\
$\mu$ & & $2.44^{a}$ & \\
\hline$\alpha_{x x}$ & 66.620 & & 58.374 \\
$\alpha_{y y}$ & 30.420 & & 29.695 \\
$\alpha_{z z}$ & 15.615 & & 15.379 \\
$\langle\alpha\rangle$ & 37.552 & & 34.483 \\
$\Delta \alpha$ & 45.448 & & 20.280 \\
$\langle\alpha\rangle$ & & $22^{b}$ & \\
\hline$\beta_{x}$ & -41.544 & & -17.953 \\
$\beta_{y}$ & 7.281 & & 5.574 \\
$\beta_{z}$ & 0.361 & & 0.312 \\
$\langle\beta\rangle$ & 42.179 & & 18.801 \\
$\langle\beta\rangle$ & & $15.5^{c}$ & \\
\hline$a, b, c$ & & \\
\multicolumn{2}{c|}{ pNA results taken from [36, 37]. }
\end{tabular}

are involved in hydrogen bond interactions [35]. It is believed that this type of hydrogen bonding is the main source of non-linear crystal like urea [36]. The mean polarizability value was calculated as $37.552 \times 10^{-24}$ and $34.483 \times 10^{-24}$ esu, respectively. These values equal to 1.5 times of that of para-nitro-aniline $(p \mathrm{NA})$ molecule which is a typical NLO material [37, 38]. The hyperpolarizability value was calculated as $42.179 \times 10^{-30} \mathrm{esu}$ for B3LYP level and $18.801 \times 10^{-30}$ esu for CAM-B3LYP level.

\subsection{Molecular surfaces}

Molecular electrostatic potential (MEP) for a molecule gives information about the presence of intra- and intermolecular interactions, predicts the reactive sites and relative reactivities towards electrophilic attack. It also provides a visual method to understand the relative polarity of the molecule. To predict reactive sites for electrophilic and nucleophilic attack for BTNP, the MEP was simulated at the B3LYP/6-31G(d) level. The negative (red and yellow) regions of the MEP are related to electrophilic reactivity while the positive (blue) regions to nucleophilic reactivity. With the more clear expression, the color scheme for the MEP surface is as follows: red for electron rich, partially negative charge; blue for electron deficient, partially positive charge; light blue for slightly electron deficient region; yellow for slightly electron rich region; green for neutral; respectively.

As it can be seen from Fig. 7, negative region is mainly localized over the oxygen atoms of the nitro and carbonyl group as well as the $\mathrm{S}$ and $\mathrm{Br}$ atoms, indicating a possible site for electrophilic attack. The maximum positive re- 


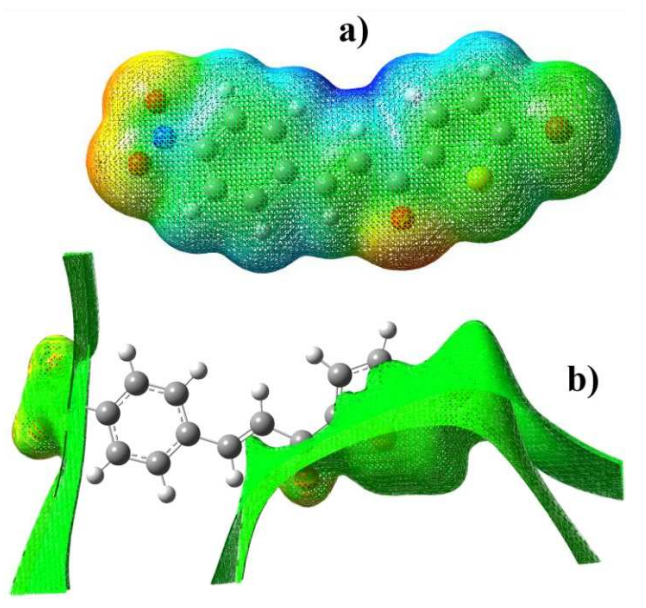

Fig. 7. (a) Molecular electrostatic potential (MEP) and (b) electrostatic surface potential (ESP).

gion is localized on hydrogens of $\mathrm{H}-\mathrm{C}=\mathrm{C}-\mathrm{H}$ group, indicating a possible site for nucleophilic attack. These sites give information about the region from where the compound can have intermolecular interactions. Therefore, Fig. 7 confirms the existence of intermolecular $\mathrm{C}-\mathrm{H} \cdots \mathrm{O}$ and $\mathrm{C}-\mathrm{H} \cdots \mathrm{S}$ interactions observed in the solid state.

\subsection{Mulliken and APT and NBO charges}

Atomic charges play an important role in quantum chemistry and much research continues to being done to refine the concept of an atomic charge. Mulliken atomic charge [39] populations give one of the simplest pictures of charge distribution and the Mulliken charges predict net atomic charges in the molecule. Atomic polar tensor (APT) is known as sum of charge tensor and charge flux tensor, leading to a charge-charge flux model [40]. The APT charges are independent of the basis sets used in the calculations whereas the Mulliken charges depend on the basis sets. Mulliken APT and NBO charges were calculated using B3LYP level, and obtained results are given in Fig. 8 as compared with each other.

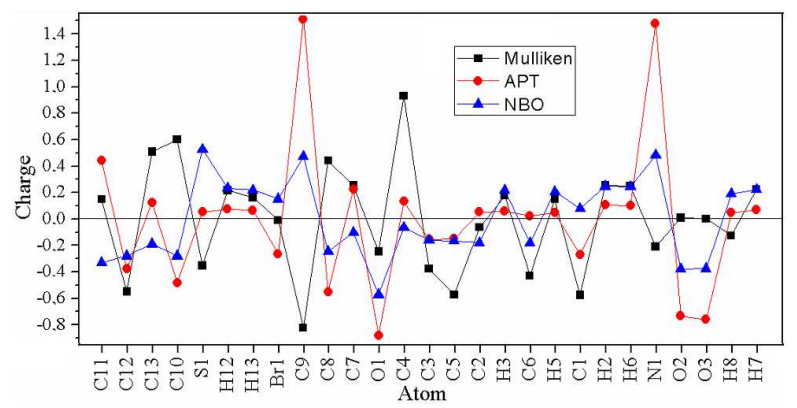

Fig. 8. Comparative of the Mulliken, APT, and NBO plots of BTNP (obtained from B3LYP level).

As can be seen from Fig. 8, C9 atom belonging to carbonyl group and N1 atom belonging to nitro group have more positive charge than other atoms, because of the electronegativity property of oxygen atom. All the protons have a positive charge while the oxygen atoms have negative charges. The charges of the carbon atoms were found to be either positive or negative. When compared the NBO, APT and the Mulliken charges for HBAH, it can be said that there is a general agreement for all atoms except that some $\mathrm{C}$ atoms.

\section{Conclusions}

A complete structural, vibrational and electronic investigation along with $\mathrm{NBO}$ and NLO analysis have been performed on the title complex using B3LYP and CAM-B3LYP levels with the $6-311++\mathrm{G}(\mathrm{d}, \mathrm{p})$ basis set. Considering that experimental and the theoretical studies are performed in different phase, it can be said that there is a good agreement between the experimental [11] and theoretical data. While the $\mathrm{C}-\mathrm{C}$ bond lengths are almost equal to each other in the free benzene ring, it was demonstrated that these bond lengths for BTNP vary in the ranges $1.385-1.407 \AA$ for B3LYP level and 1.380-1.399 $\AA$ for CAM-B3LYP level due to the substitution of benzene ring. Conformational analysis was performed, and the most stable conformers of BTNP were obtained. ${ }^{1} \mathrm{H}$ and ${ }^{13} \mathrm{C}$ NMR chemical shift calculations were performed to provide more reliable characterization. The carbon atoms bounding to oxygen, nitrogen, sulfur, and bromine atoms give peaks at more downfield regions due to the electronegativity properties of these atoms. The other aromatic carbon atoms give peaks in the range of 100-150 ppm, as would be expected. Nonlinear optical behavior of BTNP was investigated by means of the determination of the electric dipole moment, the polarizability and the hyperpolarizability. NBO analysis shows that the charge transfer, conjugative interaction occurs in BTNP. NLO analysis shows that BTNP can be used as an efficient NLO material. 3D molecular surfaces were simulated in order to obtain information about negative and positive regions which are possible sites for electrophilic and nucleophilic attack, respectively. These sites give information about the region from where the compound can have intermolecular interactions. These surfaces confirm the existence of intermolecular $\mathrm{C}-\mathrm{H} \cdots \mathrm{O}$ and $\mathrm{C}-\mathrm{H} \cdots \mathrm{S}$ interactions observed in the solid state. As a result, this paper gives information concerning structural, spectroscopic and electronic properties of BTNP using DFT levels for the first time, this study also provides the ground for the future investigations.

\section{References}

[1] P.N. Prasad, D.J. Williams, Introduction to Nonlinear Optical Effects in Molecules and Polymers, Wiley, New York 1991.

[2] H.R. Nalwa, S. Miyata, Nonlinear Optics of Organic Molecules and Polymers, CRC Press, Boca Raton, FL 1997. 
[3] S.R. Marder, J.E. Sohn, G.D. Stucky, in: ACS Symp. Series 455, American Chemical Society, Washington 1991.

[4] O. Keller, Nonlinear Optics in Solids, in: Proc. Int. Summer School, Springer, Berlin 1990.

[5] H. Pir, N. Gunay, D. Avc1, Y. Atalay, Spectrochim. Acta A 96, 916 (2012).

[6] H. Pir, N. Gunay, Ö. Tamer, D. Avcı, Y. Atalay, Spectrochim. Acta A 112, 331 (2013).

[7] A. Abbotto, L. Beverina, N. Manfredi, G.A. Pagani, G. Archetti, H.G. Kuball, C. Wittenburg, J. Heck, J. Holtmann, Chem. Eur. J. 15, 6175 (2009).

[8] J.A. Davies, A. Elangovan, P.A. Sullivan, B.C. Olbricht, D.H. Bale, T.R. Ewy, C.M. Isborn, B.E. Eichinger, B.H. Robinson, P.J. Reid, X. Li, L.R. Dalton, J. Am. Chem. Soc. 130, 10565 (2008).

[9] E.M. Breitung, C.-F. Shu, R.J. McMahon, J. Am. Chem. Soc. 122, 1154 (2000).

[10] I.D.L. Albert, T.J. Marks, M.A. Ratner, J. Am. Chem. Soc. 119, 6575 (1997).

[11] A.N. Prabhu, A. Jayarama, K. Subrahmanya Bhat, V. Upadhyaya, J. Mol. Struct. 1031, 79 (2013).

[12] M.J. Frisch, G.W. Trucks, H.B. Schlegel, G.E. Scuseria, M.A. Robb, J.R. Cheeseman, G. Scalmani, V. Barone, B. Mennucci, G.A. Petersson, H. Nakatsuji, M. Caricato, X. Li, H.P. Hratchian, A.F. Izmaylov, J. Bloino, G. Zheng, J.L. Sonnenberg, M. Hada, M. Ehara, K. Toyota, R. Fukuda, J. Hasegawa, M.I. Shida, T. Nakajima, Y. Honda, O. Kitao, H. Nakai, T. Vreven, J.A. Montgomery Jr., J.E. Peralta, F. Ogliaro, M. Bearpark, J.J. Heyd, E. Brothers, K.N. Kudin, V.N. Staroverov, R. Kobayashi, J. Normand, K. Raghavachari, A. Rendell, J.C. Burant, S.S. Iyengar, J. Tomasi, M. Cossi, N. Rega, N.J. Millam, M. Klene, J.E. Knox, J.B. Cross, V. Bakken, C. Adamo, J. Jaramillo, R. Gomperts, R.E. Stratmann, O. Yazyev, A.J. Austin, R. Cammi, C. Pomelli, J.W. Ochterski, R.L. Martin, K. Morokuma, V.G. Zakrzewski, G.A. Voth, P. Salvador, J.J. Dannenberg, S. Dapprich, A.D. Daniels, Ö. Farkas, J.B. Foresman, J.V. Ortiz, J. Cioslowski, D.J. Fox, Gaussian, Inc., Wallingford CT Gaussian 09, Revision A.1, Gaussian, Inc., Wallingford CT, 2009.

[13] R. Dennington, T. Keith, J. Millam, Semichem Inc., Shawnee Mission KS, Gauss View, Version 5 (2009).

[14] C. Lee, W. Yang, R.G. Parr, Phys. Rev. B 37, 785 (1988).

[15] A.D. Becke, J. Chem. Phys. 98, 5648 (1993).

[16] T. Yanai, D. Tew, N. Handy, Chem. Phys. Lett. 393, 51 (2004).
[17] M.J. Frisch, J.A. Pople, J.S. Binkley, J. Chem. Phys. 80, 3265 (1984).

[18] S.I. Gorelsky, A.B.P. Lever, J. Organomet. Chem. 635, 187 (2001).

[19] K. Wolinski, J.F. Hinton, P. Pulay, J. Am. Chem. Soc. 112, 8251 (1990).

[20] W.P. Oziminski, J.C. Dobrowolski, J. Phys. Org. Chem. 22, 769 (2009).

[21] J.P. Merrick, D. Moran, L. Radom, J. Phys. Chem. A 111, 11683 (2007).

[22] T. Arora, H. Ali, W.A. Burns, E. Koizumi, H. Koizumi, Chem. Phys. Lett. 502, 253 (2011).

[23] M. Silverstein, G.C. Basseler, C. Morill, Spectrometric Identification of Organic Compounds, Wiley, New York 1981

[24] G. Keresztury, in: Handbook of Vibrational Spectroscopy, Eds. J.M. Chalmers, P.R. Griffiths, Vol. 1, Wiley, New York 2002.

[25] G. Varsanyi, Assignments of Vibrational Spectra of 700 Benzene Derivatives, Wiley, New York 1974.

[26] C. Sridevi, G. Velraj, Spectrochim. Acta A 107, 334 (2013).

[27] H.O. Kalinowski, S. Berger, S. Braun, Carbon-13 NMR Spectroscopy, Wiley, Chichester 1988.

[28] F.L. Tobiason, J.H. Goldstein, Spectrochim. Acta A 23, 1385 (1967).

[29] K. Fukui, Science 218, 747 (1982).

[30] D. Avc1, Y. Atalay, Struct. Chem. 20, 185 (2009).

[31] M. Dinçer, D. Avcı, M. Şekerci, Y. Atalay, J. Mol. Mod. 14, 823 (2008).

[32] D. Avc1, Spectrochim. Acta A 82, 37 (2011).

[33] F. Weinhold, C. Landis, Valency and Bonding: A Natural Bond Orbital Donor-Acceptor Perspective, Cambridge University Press, Cambridge 2005.

[34] A.E. Reed, L.A. Curtiss, F. Weinhold, Chem. Rev. 88, 899 (1988).

[35] H. Ratajczak, S. Debrus, M. May, J. Barycki, J. Baran, Bull. Polish Acad. Sci. 48, 189 (2000).

[36] J.L. Quadar, R. Hierle, J. Appl. Phys. 48, 2699 (1977).

[37] P. Kaatz, E.A. Donley, D.P. Shelton, J. Chem. Phys. 108, 849 (1998).

[38] L.T. Cheng, W. Tam, S.H. Stevenson, G.R. Meredith, G. Rikken, S.R. Marder, J. Phys. Chem. 95, 10631 (1991).

[39] R.S. Mulliken, J. Chem. Phys. 23, 1833 (1955).

[40] V. Mukherjee, N.P. Singh, R.A. Yadav, Spectrochim. Acta A 73, 249 (2009). 